\title{
MAAILMA SÜND JA ARENG
}

Jaan Einasto

TEESID: Artiklis jälgitakse astronoomia ajalugu ja ettekujutuse muutumist maailmast, eriti viimaste kümnendite jooksul. Mitmed uued arusaamad maailmast on seotud eesti astronoomidega. Ernst Julius Öpiku (1893-1985) esimesi, 1915. aastal avaldatud töid oli pühendatud praegu aktuaalsele tumeainele ja kirjutatud ajal, kui ta oli alles Moskva Ülikooli üliõpilane. Ernst Öpik oli esimene maailmas, kes määras uudse meetodiga Andromeeda udukogu kauguse ja näitas, et udukogud on iseseisvad galaktikad väljaspool Linnuteed. Praegustel andmetel on maailma vanuseks 13,7 miljardit aastat ja teame universumi ehitust n-ö suures skaalas. Kui varem arvati, et galaktikate jaotus on enam-vähem ühtlane, iis näitasid Tartu astronoomid 1977 aastal esimestena, et galaktikad moodustavad kosmilise võrgustiku tühikute, ahelate ja superparvedega. Kosmilise võrgustiku alged tekkisid siis, kui universum oli veel väga noor, tihedamad ja hõredamad kohad tekkisid varsti pärast Suurt Pauku. Miks pole kosmilise võrgustiku skelett päris juhuslik ja kuidas ta tekkis, seda veel ei teata. Lisaks tavalisele ainele leidub Universumis tumeaine, mis koosneb arvatavasti mingitest põrkevabadest osakestest, kuid nendest ei saa moodustada aatomeid ja tihedaid kehi. Tumeainet on umbes kümme korda rohkem kui tavalist ainet, seega määravad just selle aine omadused universumi arengu suures mastaabis. Praegu on teooria peamised probleemid seotud tumeainega ja tumeenergiaga, mis on väljakutse nii füüsikutele kui astronoomidele.

MÄRKSÕNAD: tumeaine, tumeenergia, universumi ehitus, Ernst Öpik 
Viimase saja aasta jooksul on meie teadmised maailma ehitusest väga oluliselt muutunud. Eelmise sajandi alguses teati, et tähed on kauged päikesed, kuid nende ehitus, teke ja energiaallikad olid tundmatud. Samuti teati, et tähed moodustavad tähesüsteemi - Linnutee, mida samastati kogu universumiga. Oli teada tuhandete udukogude olemasolu, kuid nende loomus polnud selge. Arvati, et maailm on eksisteerinud igavesti.

Sir Arthur Stanley Eddington, kuulus astrofüüsik, kelle nimi on astronoomidele hästi tuntud, kirjutas 1914. aastal raamatu „The motion of stars and the structure of the universe“ - „Tähtede liikumine ja universumi ehitus“. Tegelikult on selles raamatus juttu ainult meie Galaktika ehitusest. See näitab, et sel ajal arvati, et kogu maailm piirdub meie Galaktikaga. Et maailm kunagi on tekkinud, sellest räägiti ka, aga rohkem teoloogilisest aspektist, teadlased ei võtnud seda väga tõsiselt.

Vana maailmapilt hakkas muutuma möödunud sajandi alguses. Mitmed uued arusaamad maailmast on seotud eesti astronoomi Ernst Julius Öpikuga (1893-1985). Üks Öpiku esimesi, 1915. aastal avaldatud töid oli pühendatud tumeainele. Sel ajal oli ta alles Moskva Ülikooli üliõpilane. Ta määras Galaktika aine tiheduse Päikese ümbruses ja leidis, et pole vajadust nähtamatu tumeda aine otsimiseks.

Paremini tuntakse tema teist tööd 1918. aastast, mil ta töötas Moskva Ülikooli juures professori kutse omandamiseks. Selles uurimuses leidis ta Andromeeda udukogu kauguse. Hiljem, kui ta oli juba Eestis, kordas ta uuemate andmete alusel seda uurimust, vastav artikkel ilmus 1922. aastal maailma kõige enam tuntud astronoomia-ajakirjas Astrophysical Journal. Ta nuputas välja lihtsa dünaamilise meetodi Andromeeda udukogu kauguse määramiseks, mida ka praegu kasutatakse. Udukogu keskosa pöörlemiskiirus oli parasjagu mõõdetud. On teada, et pöörlemiskiirusest leitav mass on seda suurem, mida kaugemal vastav objekt asub, seejuures kasvab mass kauguse suurenemisega lineaarselt. Teades kaugust, saab näiva heleduse põhjal leida galaktika koguheleduse, see kasvab kauguse suurenedes ruutseose järgi. Seega sõltub kaugusest ka massi ja heleduse võrdlemisel leitav massi ja heleduse suhe. See vahekord on lihtsalt leitav meie oma Galaktikas. Ernst Öpik määras selle suuruse Päikese ümbruse tähtede andmeid kasutades. Lõpuks arvutas ta Andromeeda udukogu kauguse, lähtudes oletusest, et aine massi ja heleduse vahekord on samasugune nagu meie oma Galaktikas. Selle tulemusel sai ta kauguseks 440 kiloparsekit. Ameerika astronoomi Edwin Hubble'i paar aastat hiljem tehtud sõltumatu uurimus kinnitas Öpiku tulemust, aga tema sai kauguseks 200 kiloparsekit. Uuemate andmete alusel on kaugus 700 kiloparsekit, seega oli Öpiku tulemus täpsem. 


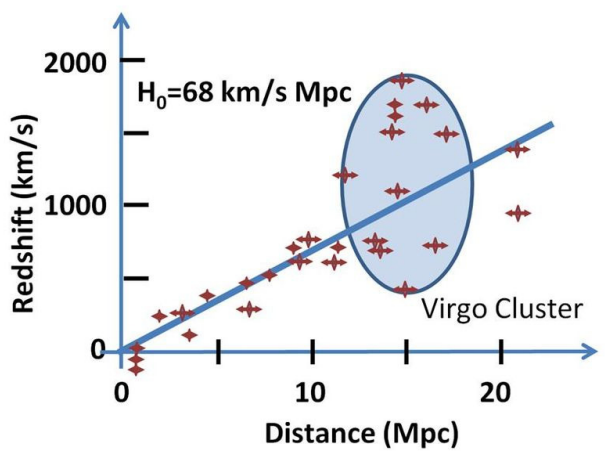

Joonis 1. Seos galaktikate kauguse ja punanihke vahel. Kaugused on antud megaparsekites, punanihked km-tes sekundis. Kaugused vastavad Hubble'i konstandi väärtusele 68 $\mathrm{km} / \mathrm{s}$ megaparseki kohta. Ovaaliga tähistatud piirkonnas asuvad Virgo parve galaktikad. Parve galaktikate punanihetel on kaks komponenti: maailma laienemisest tingitud komponent, mis on tähistatud sirge joonega, ning komponent, mille põhjustab galaktikate liikumine parves endas.

E. Hubble'i kasutada oli sel ajal maailma parim 2.5-meetrine teleskoop. Ta hakkas süstemaatiliselt udukogusid vaatlema, oletades, et tegemist on galaktikatega. Ta leidis, et peale väheste erandite on kõikide galaktikate spektrijooned tavalise asukohaga võrreldes nihkunud natuke punase spektriala poole. Oluline on seejuures see, et nihe, mida nimetatakse punanihkeks, on seda suurem, mida kaugemal galaktika asub. Füüsikast on teada, et see nn Doppleri efekt on seotud liikumisega. See ei esine ainult valguse puhul, vaid kõikide lainetuste korral, sealhulgas ka hääle korral. Näiteks kui rong läheneb ja vedur parasjagu juhtub vilistama, siis alguses on heli kõrge, kui rong mööda läheb ja vile veel jätkub, siis muutub vile toon kohe madalamaks. Seega allika lähenedes sagedus suureneb, valguse puhul muutub kiirgus sinisemaks, aga allika eemaldumisel sagedus väheneb ja lainepikkus suureneb. Valgus muutub siis punasemaks.

Oma vaatluste tulemused võttis E. Hubble kokku diagrammil, mis on esitatud joonisel 1. Alguses ta ei osanud seda seletada. Varsti märgati, et galaktikate kaugusega suurenev punanihe võib tähendada seda, et kogu maailm paisub. Paisumine on leidnud kinnitust ja on praegu üks olulisemaid fakte, mida me teame universumi kui terviku kohta.

Kui maailm paisub, siis on selge, et varem oli ta tihedamalt koos. Paisumise kiiruse järgi saab arvutada, millal paisumine algas ning millal kogu maailm oli veel kompaktselt koos. Tolleaegsete andmete järgi, kasutades siis teadaolevaid galaktikate kaugusi, tuli välja, et maailm oli väga pisike vaid mõni miljard aastat tagasi. Ernst Öpik oli üks esimesi, kes väitis, et tõepoolest maailm siis tekkis. Ta kasutas lisaks ka teisi vanuse määramise meetodeid, üks neist on näiteks hästi tuntud keemilise koosseisu analüüs. On teada, et teatud radioaktiivsed elemendid lagunevad. Kui võrrelda mingis kivimis lähte- ja laguainete suhet, siis saab hinnata kivimi va- 
nust. Niimoodi on hinnatud meteoriitide vanust, samuti ka Maa enda kivimite vanust. Need vanused on kõik samas suurusjärgus, Öpiku andmetel veidi üle mõne miljardi aasta. Nüüd, kui galaktikate kaugused on paremini teada ning ka teised meetodid on täpsustunud, siis annavad kõik need meetodid suurema vanuse. Praegustel andmetel on maailma vanuseks 13,7 miljardit aastat.

Kuidas paisumine toimub? Selgub, et see sõltub universumi tihedusest. Kui tihedus on väga väike, siis ei ole midagi, mis paisumist takistaks, kui tihedus on väga suur, siis on selge, et gravitatsioon saavutab kunagi uuesti ülekaalu, seega universum tõmbub pärast kokku. Ongi räägitud pulseeruvast maailmast - alguses maailm paisub, siis kukub jälle kokku ning nii edasi.

Joonisel 2 on horisontaalteljel näidatud universumi vanus miljardites aastates ja vertikaalteljel universumi suurus, mõõdetuna keskmise galaktikatevahelise kaugusega. Kui universum oleks väga tihe, siis oleks ta

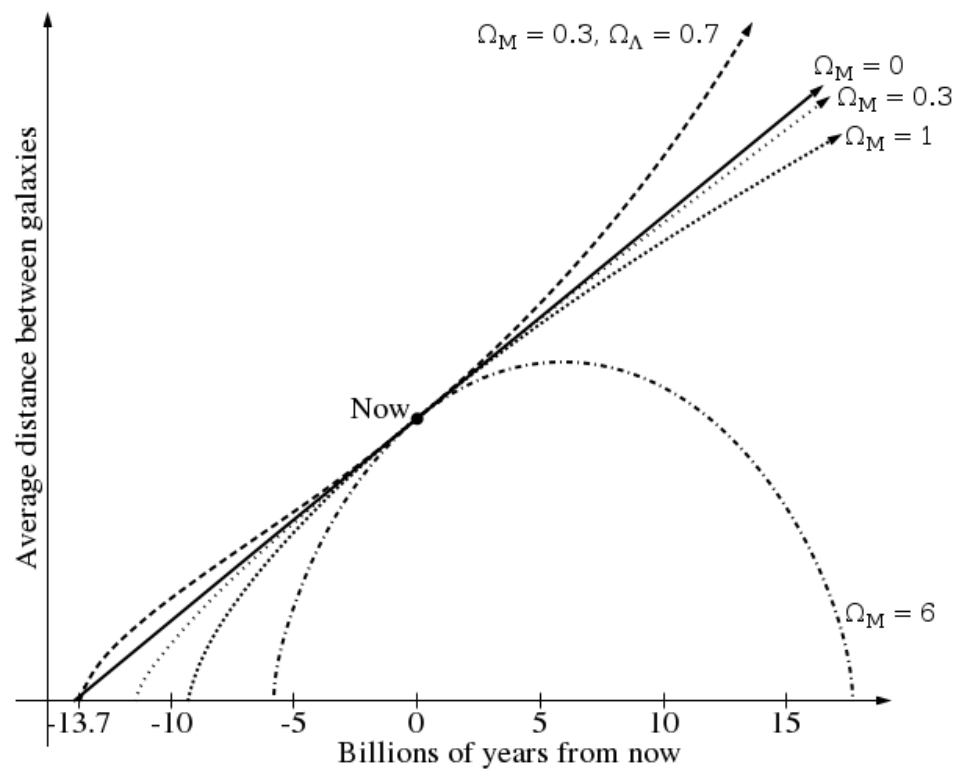

Joonis 2. Galaktikate keskmise omavahelise kauguse sõltuvus maailma vanusest. Vanus on arvestatud miljardites aastates praegusest hetkest, keskmise kauguse ühikuks on võetud praegune kaugus. Eri jooned näitavad kauguse muutumist nii minevikus kui ka tulevikus, sõltuvana aine ja tumeda energia tihedusest praegu. Aine tihedus on tähistatud $\Omega_{\mathrm{M}}$, tumeda energia tihedus $\Omega_{\Lambda}$, mõlemad kriitilise tiheduse ühikutes. 
tekkinud suhteliselt hiljuti ning ta kukuks uuesti kokku. Seda tihedust, mille puhul ta püsib nii-öelda parasjagu tasakaalus, kutsutakse kriitiliseks tiheduseks. Astronoomid väljendavad aine tihedust kriitilise tiheduse ühikutes suure oomegaga, nendes ühikutes on kriitiline tihedus seega üks. Uuemad andmed näitavad, et aine tihedus on kriitilisest väiksem, selle probleemi juurde me tuleme hiljem.

Kui me vaatame tähistaevast, siis näeme tähti ja galaktikaid. Kõige heledam galaktika põhjataevas on Andromeeda galaktika, ta on palja silmaga vaevalt näha. Kõik kaugemad galaktikad on pisikesed udulaigud, mis on nähtavad vaid teleskoopidega ning mis ei paista tähtede foonil eriti silma. Varem arvati, et galaktikad paiknevad ruumis enam-vähem juhuslikult, vaid väike osa nendest koondub galaktikaparvedesse ja superparvedesse. 1970. aastate keskel hakkas selguma, et galaktikad moodustavad pikki ahelaid ning nendevaheline ruum on praktiliselt tühi. Rikkamad ahelad koosnevad galaktikaparvedest ja on koondunud superparvedesse, vaesemad ahelad koosnevad galaktikagruppidest ja üksikgalaktikatest.

Selleks, et teha täpsemini kindlaks, kuidas galaktikate maailmas on aine jaotunud, ehitati spetsiaalne teleskoop. Projekti rahastas Sloani fond. Alfred Sloan oli Ameerika kompanii General Motors üks juhte, ta lõi omanimelise fondi, mis rahastab originaalseid uurimusi ja teadusharidust. See fond rahastas ka nüüd tema nime kandvat taevaülevaadet. Sloani teleskoobi abil mõõdeti kõikide galaktikate ja ka muude objektide heledused kuni teatud kindla piirini. See piir galaktikate fotomeetriliste parameetrite määramiseks on umbes 22. tähesuurus, spektrite määramisel 17.7-s tähesuurus punases spektripiirkonnas. Spektrite saamiseks tehti sellele küllaltki suure vaateväljaga teleskoobile plaat, millesse puuriti galaktikate asukohta augud, kuhu viidi valgusfiibrid. Need koondati spektograafi. Nii saadi korraga kuuesaja galaktika spektrid. Öö jooksul saadakse mitu kuuesaja spektriga pilti ja umbes kümne aasta jooksul on ära skaneeritud kogu põhjataevas. Kokku on sellisel viisil mõõdetud ligi miljoni galaktika spektrid ja määratud punanihked. Need annavad galaktikate kauguse, spektritest saab aga ka palju muud kasulikku infot galaktikate ehitusest ja tähelisest koosseisust.

Joonisel 3 on kujutatud Tartu astronoomide poolt Sloani ülevaate abil koostatud vaade taevale, kus on näha ainult galaktikad. See on arvuti abil konstrueeritud sfääriline kiht, seega on kõik objektid meist samal kaugusel. Kihi paksuseks on kümme megaparsekit, see on kompaktse süsteemi läbimõõt. On näha galaktikate superparved ning nende vahel asuvad suured tühjad alad. Kui vaatame mõnda piirkonda lähemalt, siis näeme, et superparved koosnevad tegelikult galaktikaparvedest ja galaktikate ahelatest. Kokku moodustavad superparved ja galaktikateahelad võrgustiku, 
mida kutsutakse kosmiliseks võrgustikuks. Meie kasutasime omal ajal väljendit „rakustruktuur“. Rakk on hõre ala, mis on ümbritsetud rikaste superparvedega. Rikast superparvede kogumit pildi alumises osas kutsutakse Sloani seinaks. Sloani taevaülevaate koostamine on viimase paari-kolmekümne aasta kõige olulisem saavutus kosmoloogias.

Nüüd me teame universumi ehitust n-ö suures skaalas. Varem arvati, et galaktikate jaotus on enam-vähem ühtlane, kuid selgub, et on olemas kosmiline võrgustik tühikute, ahelate ning superparvedega. See on oluline, sest tuleb välja, et kosmilise võrgustiku alged tekkisid siis, kui universum oli veel väga noor. Tihedamad ja hõredamad kohad tekkisid varsti pärast Suurt Pauku. Alguses oli universumi paisumine väga kiire, seal olid teatud väikesed tiheduse fluktuatsioonid. Nendest fluktuatsioonidest kasvasidki aja jooksul välja kõik universumi struktuuri elemendid. Üks meie enda töögrupi viimaseid kõige huvitavamaid tulemusi on avastus, et nende suurte struktuuride alged ehk kosmilise võrgustiku skelett sündis juba väga ammu. Miks pole kosmilise võrgustiku skelett päris juhuslik ning kuidas ta tekkis, seda me veel ei tea.

Järgmiseks räägime foonkiirgusest. Kui universum paisub, siis ta jahtub. Järelikult oli ta varem kuumem, küsimus on selles, kui kuum. Mõned teoreetikud arvasid juba ammu, et universum võis olla nii kuum, et algne kiirgus võiks olla veel praeguse ajani säilinud. Ja tõepoolest, 1964. aastal avastasidki Ameerika raadioinsenerid Arno Penzias ja Robert Wilson Belli laborist Holmdelist kosmilise foonkiirguse. Nii kutsume seda kiirgust praegu. See on jäänuk omaaegsest kuumast universumist. Kuna universum paisub, siis tema temperatuur langeb. Alguses oli temperatuur nii kõrge, et aine oli ioniseeritud nagu praegu tähtede sisemuses. Selline kuum gaas ehk plasma on läbipaistmatu, sest footonid neelduvad aineosakestes. Temperatuuri langedes muutub aine neutraalseks ja universum läbipaistvaks. Sel rekombinatsiooniajal oli temperatuur pisut üle tuhande kraadi, praegu on kiirguse temperatuur ainult 2,7 kraadi üle absoluutse nulli.

Foonkiirgus on väga nõrk ja läks pikka aega, enne kui seda õnnestus mõõta. Penzias ja Wilson avastasid foonkiirguse juhuslikult. Nende ülesandeks oli raadioside parandamine. Nad otsisid igasuguseid müraallikaid ning leidsid niisuguse müra, mida ei olnud kuidagimoodi võimalik elimineerida. Selgus, et see ongi kosmiline müra. Nüüd on hakatud seda detailselt uurima. Üks foonkiirguse iseärasus on see, et tema temperatuur on väga ühtlane. Selgub, et temperatuuri kõikumised on ainult üks sajatuhandik temperatuurist endast. Need kõikumised avastati esmakordselt 1992. aastal COBE-nimelise satelliidiga. Satelliit COBE oli esimene, millega õnnestus foonkiirguse kõikumisi mõõta. Kümme aastat hiljem õnnestus täpsema satelliidiga WMAP näha temperatuuri fluktuatsioone detail- 
semalt. Esiteks oli paranenud ruumiline lahutusvõime ja teiseks ka tundlikkus, nii et kui enne olid näha vaid temperatuuripildi suured laigud, siis nüüd on näha juba peenstruktuur. Praegu on lendamas uus satelliit Planck, mille täpsus on veel umbes kümme korda kõrgem.

Miks on foonkiirguse uurimine nii oluline? Foonkiirguse detailid sõltuvad väga oluliselt sellest, millised olid kiirgust tekitava gaasi omadused. Viimased sõltuvad kosmoloogilistest parameetritest: missugune on maailma tihedus, koosseis, kui palju on seal tavalist meile tuntud ainet ja kui palju on tumeainet - kokku annab foonkiirgus meile väga täpse informatsiooni universumi üldiste omaduste kohta. Joonisel 4 on näidatud temperatuuri jaotus taevas satelliidi WMAP andmetel.

Eelnevas oli juttu tavalisest ainest ja tumeainest. Tumeaine olemasolu selgus pikkamisi samm-sammult. Tumeaine avastamisel on ka meie astronoomidel oma roll olnud. Kuni 1970. aastateni arvasid astronoomid, et kogu aine, mis maailmas leidub, on nähtav, kas siis tähtede, planeetide, kosmilise tolmu või udukogudena. Aga selgus, et on veel midagi, mida me ei näe, kuid mis on küllaltki massiivne, tuleb välja, et koguni massiivsem kui kõik nähtav aine kokku.

Esimesed signaalid tumeaine võimalikust olemasolust tulid galaktikate liikumisest parvedes. Ameerika astronoom Fritz Zwicky mõõtis 1933. aastal Coma galaktikaparve liikmete kiirused parve keskme suhtes ja leidis, et galaktikad liiguvad liiga kiiresti. Selleks, et parv laiali ei lendaks, peab parve kogumass olema vähemalt kümme korda suurem kui temas leiduvate galaktikate kogumass. Ta oletas, et galaktikate suurte kiiruste seletamiseks peab parves leiduma veel mingi nähtamatu tume aine. Millegipärast ei pannud astronoomiline üldsus seda väga olulist tulemust tähele.

Järgmised signaalid tumeaine olemasolust tulid galaktikate pöörlemise uurimisel. Joonisel 5 on esitatud USA astronoomi Vera Rubini ja tema kolleegide poolt leitud mitmete galaktikate pöörlemiskõverad. Galaktikad on keskelt tihedamad, galaktika äärealal kahaneb tema tihedus kiiresti, seetõttu äärealadelt enam massi juurde ei tule. Seega peaks galaktikate äärealades tähtede liikumine ümber galaktika keskme olema selline nagu planeetidel päikesesüsteemis, kus praktiliselt kogu mass on koondatud Päikesesse, sest planeetide massid on võrreldes Päikese massiga tühised. Vastavalt Newtoni seadusele kauguse suurenedes gravitatsioon nõrgeneb ning planeedi tiirlemiskiirus ümber Päikese väheneb: Maa liigub aeglasemalt kui Veenus, Marss liigub veel aeglasemalt, Jupiter veelgi aeglasemalt ja nii edasi. Galaktikate puhul selgub, et nende nähtav osa lõpeb umbes 20 kiloparseki kaugusel tsentrist. Seega võiks oodata, et galaktika pöörlemiskiirus hakkab perifeerias kahanema nagu päikesesüsteemiski. Rubini 


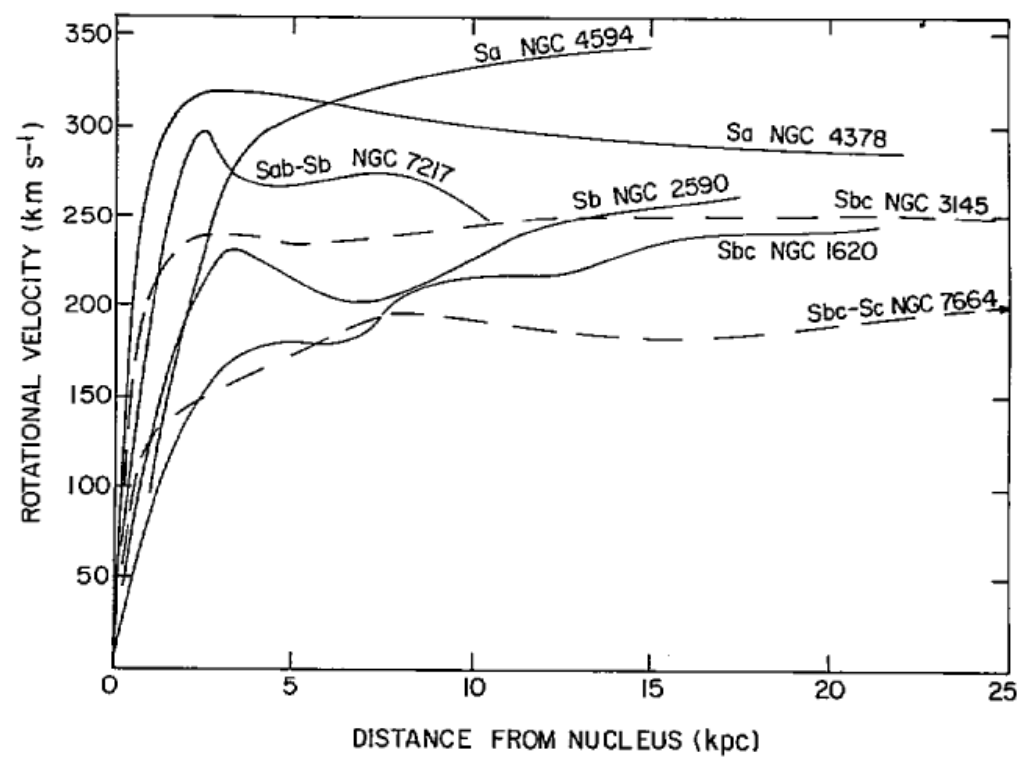

Joonis 5. Seitsme spiraalgalaktika pöörlemiskõverad Vera Rubini ja tema kolleegide andmetel. Horisontaalteljel on antud kaugus vastava galaktika tuumast kiloparsekites, vertikaalteljel galaktika pöörlemiskiirus km-tes sekundis.

ja teiste vaatlused näitasid, et see pole nii - pöörlemiskiirus on galaktikate perifeersetes piirkondades praktiliselt konstantne.

Polnud selge, kuidas pöörlemiskiiruse konstantsust seletada. Alguses arvati, et tegemist polegi tõelise pöörlemiskiirusega, vaid aine radiaalse liikumisega galaktika keskme suhtes. Teine võimalus konstantse pöörlemiskiiruse seletamiseks on oletada, et galaktikate ümber leidub mingi aine, mis ei kiirga, aga oma külgetõmbega paneb galaktikad kiiremini pöörlema. Ka meie lähtusime oletusest, et galaktikaid ümbritseb nähtamatu tume kroon. Tahtsime teada, kui kaugele see kroon ulatub. Selleks kasutasime testkehadena galaktikate kaaslasi. Galaktikatel on kaaslased, nende liikumist galaktika suhtes saab kasutada krooni sisemise osa massi hindamiseks. Teatavasti mingi keha liikumisel teise keha ümber tunneb testkeha ainult seda massi, mis jääb tema orbiidi sisse. Joonisel 6 on toodud sisemise massi kasv vastavalt kaaslase orbiidi raadiusele. Galaktika nähtav osa lõpeb umbes 20 kiloparseki kaugusel, seega suurematel kaugustel tähtedest enam galaktikale massi juurde ei tule ning nähtava osa mass jääb konstantseks. Aga väljaspool on veel midagi, mis kasvatab kauguse suure- 


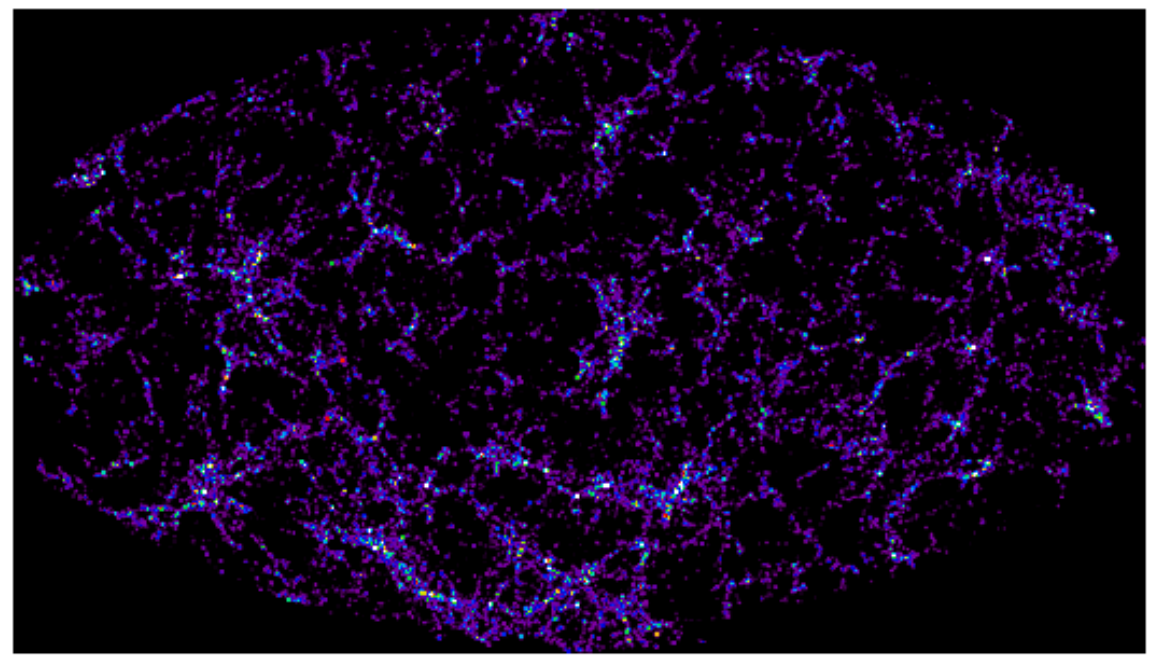

Joonis 3. Galaktikate heledustiheduse väli Sloani taevaülevaate põhjal.

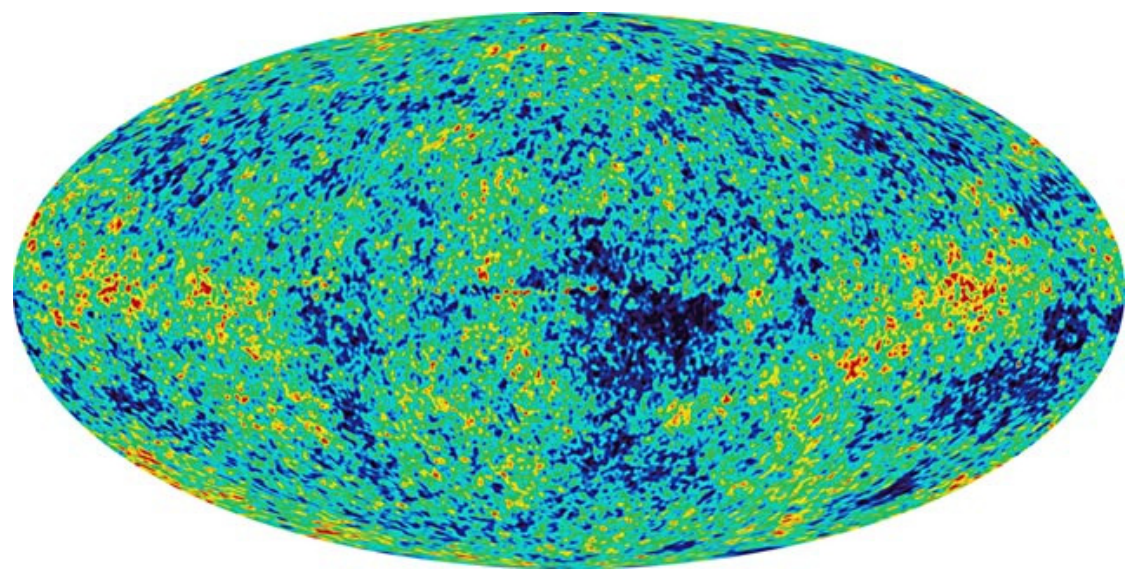

Joonis 4. Satelliidiobservatooriumi WMAP abil leitud foonkiirguse temperatuuride jaotus taevasfääril. Kollased ja punased piirkonnad tähistavad temperatuure pisut üle keskmise, roheline keskmist temperatuuri ja sinised alad keskmisest madalamat temperatuuri. 

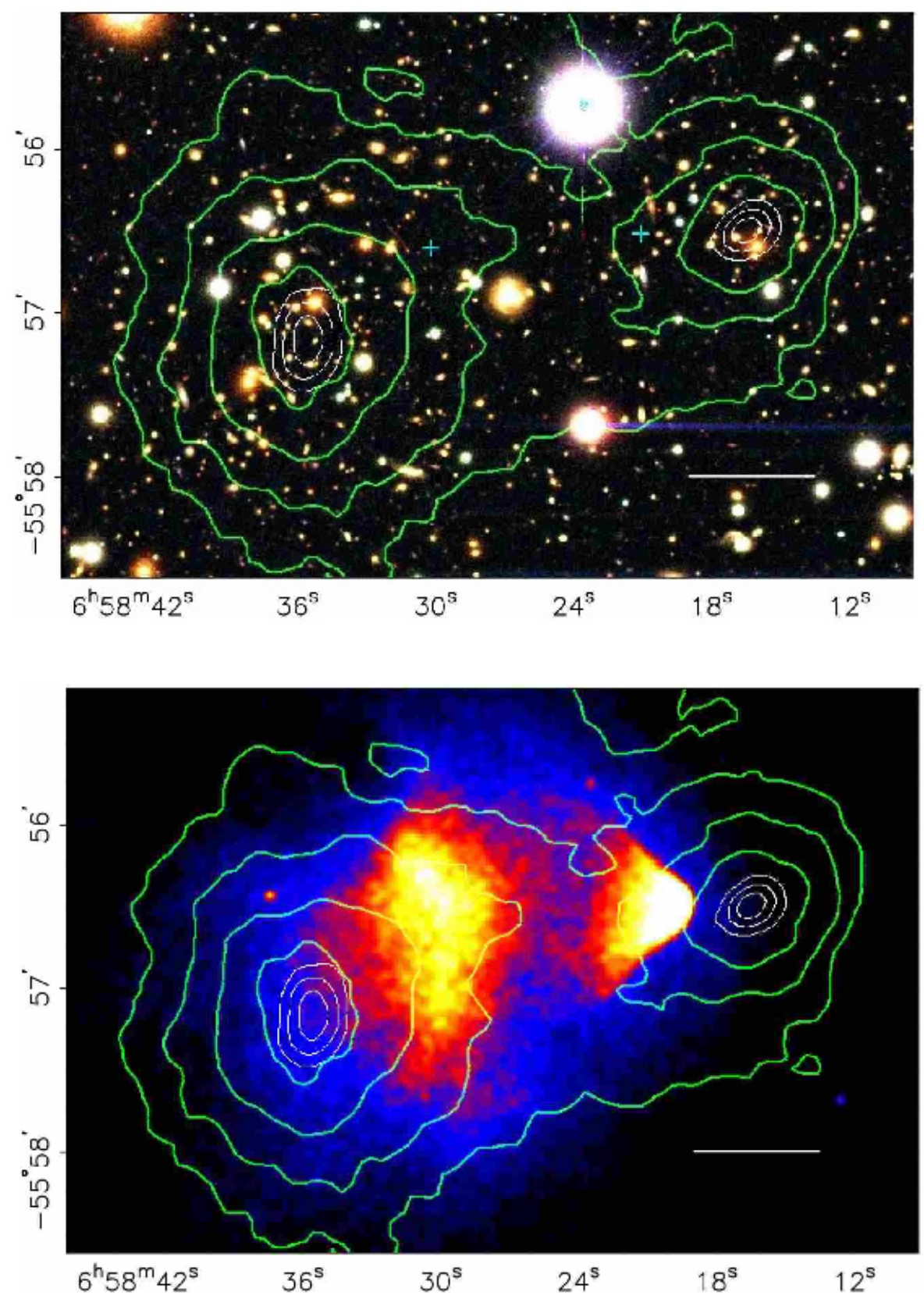
Joonis 7. Ülemisel pildil on kujutatud värvifoto kaksikparvest 1E0657-558, alumisel pildid sama parve kujutis röntgenkiirtes. Esimene pilt on saadud Las Campanase 6.5-m Magellani nimelise teleskoobiga, teine Chandra X-kiirte orbitaalse observatooriumiga. Rohelised kontuurid mõlemal pildil näitavad massi paigutust parves, mis on leitud nõrga gravitatsiooniläätse efekti abil, kasutades Hubble'i kosmoseteleskoobi abil saadud kaugete galaktikate kujutiste moonutusi (Clowe'i ja kaasautorite andmetel).

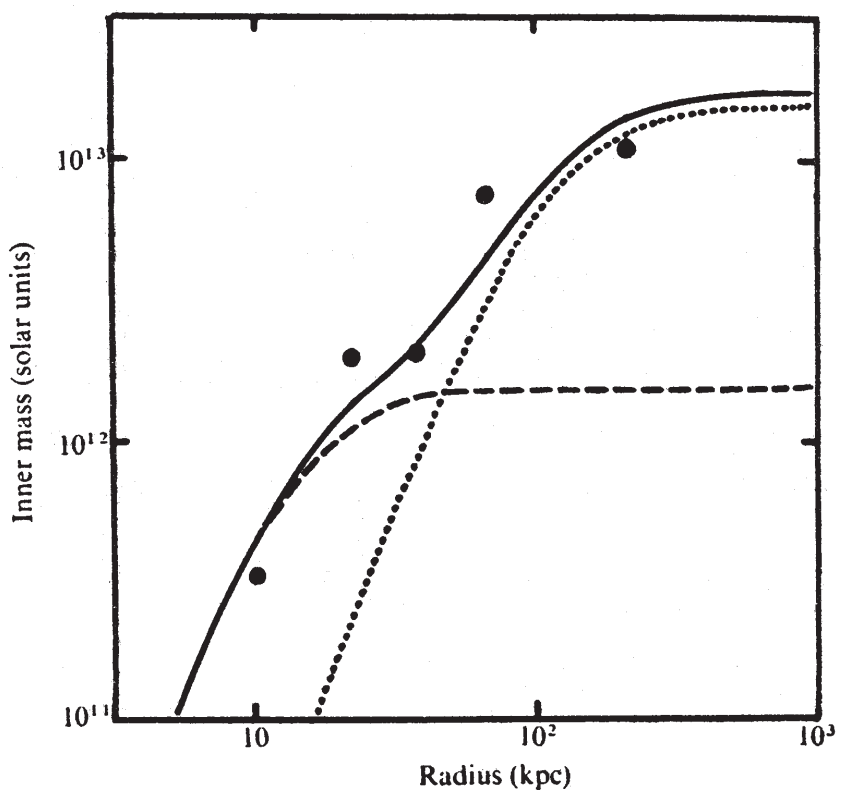

Joonis 6. Hiidgalaktikate sisemise massi sõltuvus raadiusest Jaan Einasto, Ants Kaasiku ja Enn Saare andmetel. Mass on antud Päikese massi ühikutes, raadius kiloparsekites. Katkendlik joon kujutab sisemist massi, mis on põhjustatud galaktikate nähtavatest populatsioonidest, punktiirjoon tumeda krooni sisemist massi ja pidev joon summaarset sisemist massi. Punktidega on märgitud sisemise massi väärtused, mis on arvutatud 105 kaaslasgalaktika suhtelise kiiruse põhjal. 
nedes galaktika massi. Nagu näitab kaaslaste liikumise analüüs, on kroon umbes kümme korda suurem ja massiivsem kui galaktika nähtav osa.

Esialgu me ei teadnud, millest kroon on tehtud. Nüüdseks on selgunud, et kroon koosneb niisugusest ainest, mis on tavalise ainega võrreldes hoopis teistsuguste omadustega. Sellist nähtamatut ehk tumedat ainet kutsutakse mitte-barüonaineks. Tavaline ehk barüonaine koosneb sellisest osakestest, mis moodustavad aatomeid, molekule ja suuremaid moodustisi. Tumeaine koosneb arvatavasti ka mingitest osakestest, kuid nendest ei saa moodustada aatomeid ja tihedaid kehi. Tumeainet on umbes kümme korda rohkem kui tavalist ainet, seega määravad just selle aine omadused universumi arengu suures mastaabis.

Tumeaine osakesi pole seni leitud ning mõnedel teoreetikutel tekkis idee, et vahest polegi tumeainet olemas ning galaktikate pöörlemiskiiruse konstantsus on tingitud sellest, et suurtel kaugustel Newtoni gravitatsiooniseadus ei kehti päris täpselt. Sellise modifitseeritud Newtoni dünaamika (MOND) abil püüti seletada nii galaktikate pöörlemiskiirusi kui ka galaktikaparvede dünaamikat. Seega seisab astronoomidel ees ülesanne kindlaks teha, kas tumeaine on olemas või on hoopis vaja täiendada Newtoni teooriat.

Hiljuti avastati galaktikate kaksikparv, kus on ilmsed jäljed parvede kokkupõrkest. See galaktikate kaksikparv on näidatud joonisel 7. Väiksem parv, mida nimetatakse kuuliks, on suuremast läbi läinud. Neid parvi on uuritud tavalises valguses ja röntgenkiirtes. Tavalises valguses näeme galaktikaid. Selgub, et parvede galaktikad omavahel ei põrku, lihtsalt kaks parve lähevad üksteisest läbi. Mõlemas parves leidub ka gaasi. Parvedes leiduv gaas on kuum, sest gaasiosakeste liikumine on tasakaalus parve gravitatsiooniväljaga. Seetõttu on gaasi temperatuur kõrge, umbes 100 miljonit kraadi. Selline gaas kiirgab röntgenkiirgust. Väiksema parve läbimisel suuremast gaasiosakesed põrkuvad ja mõlema parve gaasipilved jäävad pisut maha parvest endast. Väiksema parve gaasipilve kuju viitab lööklainele, sarnaselt püssikuuli liikumisel tekkiva lööklainega.

Uurides parvede taga asuvate kaugete galaktikate kujutiste moonutusi, saab kindlaks teha massi jaotust parves. Seda nimetatakse gravitatsioonilise läätse efektiks. Rohelised ringid pildil näitavad seda, kuidas aine on jaotunud, võttes arvesse gravitatsioonilise läätse efekti. Selgub, et mass on jaotunud täpselt samamoodi nagu galaktikad, aga gaasi jaotus erineb sellest, gaas n-ö jääb sellest maha. Parves leiduv tavaline aine on põhiliselt gaas, galaktikate nähtavate osade mass on vaid umbes kümnendik gaasi massist. Seega näitab massijaotuse ja gaasijaotuse võrdlus seda, et peamine mass ei saa olla tavaline gaas. Mass on peitunud ainesse, mille 
osakesed ei põrku parvede teineteisest läbiminekul. Teiste sõnadega - see ei saa olla ei tähed ega gaas, vaid põrkevabadest osakestest koosnev aine. Aga just selliste omadustega ongi mittebarüon-osakestest koosnev tumeaine.

Kuna looduses pole mitte midagi ilma põhjuseta, siis tekib küsimus: kui tumeainet on kümme korda rohkem kui tavalist ainet, siis milleks tumeainet tarvis on? Selgub, et tumeaine on vajalik selleks, et kogu ülejäänud maailm saaks areneda. Universumi arengu varajasel perioodil oli temperatuur nii kõrge, et intensiivne kiirgus ei võimaldanud aine tihedushäiritustel kasvada. Tihedushäiritused on umbes sama suured nagu temperatuurihäiritused. Foonkiirguse mõõtmiseks ehitatud satelliitobservatooriumi WMAP abil tehtud mõõtmised näitasid, et temperatuurihäiritused on umbes üks sajatuhandik temperatuuri enda väärtusest.

Arvutused näitavad, et struktuur saab välja areneda vaid juhul, kui tihedushäiritused on vähemalt sada korda suuremad. Vastasel korral gaas hajuks ja mingisuguseid struktuure tekkida ei saaks, ei tähti ega galaktikaid. Kui oletada, et põhiline aine universumis on selline, mis tavalise aine ja kiirgusega ei interakteeru, et ta on nii-öelda vaba, siis tumeaines saavad hakata tihendid tekkima umbes sada korda varem. Selleks ajaks, kui temperatuuri langedes kiirguse mõju lakkab, on tumeainest võrgustik juba välja kujunenud. Tavaline aine voolab tumeaine tihenditesse ja areng läheb edasi. Teiste sõnadega, meie oleme olemas ainult tänu sellele, et on olemas tumeainest tekkinud vundament. See vundament võimaldab kogu pealisehituse tekke, alates tähtedest ja nende kogumitest. Tähtede sees toimub keemiliste elementide süntees, millest rääkis Ene Ergma. Tähed on vajalikud selleks, et saaks tekkida keemilised elemendid, mis on vajalikud elu ja ka meie tekkimiseks. Seega on maailmas asjad omavahel väga seotud.

Nüüd vaatleme aine ja energia jaotust universumis. Teoreetiliselt peetakse eelistatuks seisukohta, et aine ja energia kogutihedus on võrdne kriitilisega. Universum on paisunud miljardeid kordi. Kui tihedus oleks natukenegi erinenud kriitilisest, siis oleks see erinevus universumi paisudes suurenenud. Kui tihedus oleks veidi väiksem kriitilisest, siis oleks universum kiiresti laiali paisunud, kui aga tihedus oleks olnud alguses pisut suurem kriitilisest, oleks universum kiiresti kokku kukkunud. Järelikult peab olema mingi mehhanism, mis teda täpselt koos hoiab. Vaatlustest selgub, et tavalist ainet on ainult umbes neli protsenti kriitilisest tihedusest, kusjuures sellest neljast protsendist vaid umbes kümnendik on koondunud tähtedesse ning ülejäänu on kosmiline gaas. Seega ainet, millest meie ise oleme tehtud, on kaugelt alla protsendi aine koguhulgast. Umbes kolmandiku kriitilisest tihedusest moodustab tumeaine. Aga kaks 
kolmandikku on puudu, selle kohta ei olnud veel üsna hiljuti midagi teada. Teoreetikud oletasid juba alates Einsteinist, et võib eksisteerida mingi energia, mis tõstab aine ja energia koguhulga kriitiliseks, aga kindel ei olnud selles keegi.

Viimase kümne aasta jooksul on tehtud mitmeid eksperimente, et selgitada välja aine kogutihedus. Üheks võimaluseks on võrrelda supernoovasid meie ligidal ja kaugemal ruumis. Supernoovade kaugusi saab määrata sõltumatult nende punanihkest, sest nende absoluutsed heledused on üsna konstantsed, mistõttu näiva ja absoluutse heleduse võrdlusest saame leida kauguse. Kui võrrelda selliseid fotomeetrilisi kaugusi punanihetest saadud kaugustega, saame kindlaks teha, kui kiiresti paisub maailm praegu meie ligemal ümbruses ja kui kiiresti ta paisus minevikus suurtel kaugustel. Selgub, et universum paisub üha kiirenevalt. Kiireneva paisumise põhjustajaks on tume energia. Supernoovade eksperiment oli esimene kindel tõend tumeda energia olemasolust.

Teine tõend tumeda energia olemasolust saadi kosmilise foonkiirguse mõõtmistest. Need mõõtmised näitasid, et aine ja energia kogutihedus on võrdne kriitilisega. Erinevust aine tiheduse (tavaline ja tumeaine koos) ja kogutiheduse vahel saab seletada vaid täiendava energia olemasoluga, mis koos ainega annabki kogutiheduseks kriitilise.

Tumeda energia olemasolust sõltub, kui kiiresti maailm eri epohhidel paisub. Nimelt on tumedal energial omadus, mida kutsutakse antigravitatsiooniks, tal on negatiivne rõhk, ta puhub maailma laiali. Antigravitatsioon on võrdeline ruumalaga, seega universumi arengu varasel etapil, kui universum oli praegusest väiksem, oli ka tumeda energia roll väike või puudus üldse. Epohhil, mis vastab punanihkele 0.7, oli aine tihedus ja tumeda energia tihedus võrdsed, edaspidi saavutas tume energia ülekaalu. Seetõttu paisub universum nüüd üha kiirenevalt. See on viimase kümne aasta olulisim saavutus kosmoloogias.

Mis puutub tumeda aine ja tumeda energia olemusse, siis sellest on veel väga vähe teada. Mõned juhtivad teoreetikud on avaldanud arvamust, et füüsika praegune seisund meenutab olukorda sada aastat tagasi, kui klassikaline füüsikaline maailmapilt sai valmis. Siis tundus, et kõik on enam-vähem selge, on vaid paar eksperimenti, mis ei klappinud varasemate andmetega. Nende eksperimentide tõlgendamisest kasvas välja kogu nüüdisaegne füüsika: tuumafüüsika, kvantfüüsika jne. Tumeaine ja tume energia on nähtused, mille olemusele pole veel jälile saadud. Füüsikud pole vastavaid osakesi ja välju leidnud. Võib arvata, et 21. sajandi füüsika ja astronoomia üks põnevamaid küsimusi ongi nende nähtuste selgitamine. 
Kahekümnenda sajandi kõige suurem ja olulisem tulemus oli aine ehituse selgitamine. Avastati, et aine koosneb aatomitest, aatomites on tuumad ja elektronid, mis omakorda koosnevad väiksematest osakestest. Mis selgub tumeaine ja tumeda energia uurimisest, ei tea veel keegi, kuid igal juhul on see põnev. On tore, et Tartu astronoomid on tumeda aine osas üht-teist öelnud, ning me tahame ka edaspidi nendes otsingutes kaasa rääkida. Siin on küllaltki oluline sõna füüsikutel. Kõige võimsam eksperiment, mida praegu tehakse, on Genfi lähedal asuv suur osakeste põrkur. Meie Tallinna kolleegid Martti Raidali juhtimisel osalevad selles eksperimendis. Meil on nende grupiga tihe koostöö. Loodame, et kui me paneme kokku ühelt poolt füüsikute poolt tulevad andmed, teiselt poolt astronoomidelt tulevad andmed, siis on loota, et sealt tuleb välja midagi huvitavat.

Seni on põhiline info tulnud astronoomiast. Seesama pilt, universumi rakustruktuur, kus on kõik need superparved, on praegusel hetkel kõige olulisem informatsiooniallikas tumeaine osakeste kohta. Nimelt sõltub kosmilise võrgu struktuur sellest, missugused on tumeaine osakeste omadused.

Kokkuvõtteks võime öelda, et maailmapilt muutus ja täienes viimase saja aasta jooksul väga palju. Praegu on peamised probleemid seotud tumeainega ja tumeenergiaga, see on väljakutse nii füüsikutele kui astronoomidele. Siin tekib ka uus küsimus, mida teoloogid on küsinud juba ammu: mis oli siis, kui vanajumal maailma lõi? Tuleb välja, et see polegi rumal küsimus, astronoomid ja füüsikud murravad praegu pead selle probleemi selgitamisel. Oletatakse, et on võimalik ka niisuguse universumi sünd, kus tavaline aine ei saagi tekkida. Sellises universumis ei saa olla vaatlejat. Vaatleja saab olla vaid universumis, kus moodustub tavaline aine. Millest kujunevad arengu käigus tähed, kus toimuvad tuumareaktsioonid, mis valmistavad ette planeetide tekke ja lõpuks ka elu tekke.

Litereeris Triin Einasto

\section{Summary}

\section{THE FORMATION AND THE EVOLUTION OF THE UNIVERSE}

In this talk I discuss the development of ideas on the formation, evolution and structure of the Universe, in particular during the last decades. A number of new ideas on the structure and evolution of astronomical objects are associated with Estonian astronomers. As a student of the Moscow University Ernst Julius Öpik (1893 - 1985) in its first publication in 1915 
discussed the possibility of the presence of invisible matter in the disk of our Galaxy. Ernst Öpik was the first astronomer who determined using a novel method the distance to the Andromeda nebula and demonstrated the spiral nebulae are distant galaxies outside the Milky Way. According to classical paradigm galaxies are more-or-less randomly located in space. In 1977 Tartu astronomers showed that galaxies are concentrated to chains and superclusters leaving huge voids without any visible objects. Seeds of the cosmic web formed in the very early Universe soon after the Big Bang from tiny fluctuation of the density. It is not clear how the skeleton of the cosmic web formed and why it is not completely random. In addition to ordinary matter there exists in the Universe dark matter which consists of non-baryonic particles. These particles do not interact with ordinary matter and do no form compact bodies like atoms and other dense objects. The total amount of dark matter in the Universe exceeds the amount of ordinary matter about tenfolds, thus properties of dark matter particles determine the evolution of the Universe on large scales. In addition there exists in the Universe also dark energy. To understand properties of dark matter and dark energy is the greatest challenge for modern physics and astronomy.

KEY WORDS: dark matter, dark energy, the structure of the Universe, Ernst Öpik 